\title{
laborhifórico
}

ISSN 2359-6910

https://revistas.ufrj.br/index.php/lh/

FONTES PRIMÁRIAS

Recebido em 7 de fevereiro de 2019

Aprovado em 17 de maio de 2019

\section{Histórias que as cartas pessoais contam: notícias de um casamento}

DOI: https://doi.org/10.24206/lh.v5iEspecial.27031

\section{Letycia Dias Mallet}

Licencianda em Letras: Português-Espanhol na Universidade Federal do Rio de Janeiro. Foi bolsista de Iniciação Científica na mesma instituição pelo Departamento de Letras Vernáculas. Atualmente é bolsista pelo Conselho Nacional de Pesquisa (CNPQ), na mesma categoria. Participa do Laboratório de Estudos Filológicos da UFRJ (LabEFil) e do Laboratório de História da Língua Portuguesa da UFRJ (HistLing). Faz parte da equipe de edição da Revista LaborHistórico.

E-mail: letycia.mallet@hotmail.com ORCID: https://orcid.org/0000-0002-3439-1471 


\section{Resumo}

Este texto tem como objetivo disponibilizar uma edição conservadora de um dos documentos do fundo documental Didola, com o intuito de que essa edição sirva como fonte primária para o estudo de demais pesquisadores. Esse fundo documental foi batizado como Didola, em homenagem à forma como era conhecida a matriarca da família e destinatária de muitas das cartas que estão presentes no fundo. É composto, principalmente, por cartas pessoais de indivíduos não-ilustres, cujas redes se materializam principalmente na região sudeste do Brasil. O recorte temporal dos documentos data desde a primeira metade do século XX até a década de 80 desse mesmo século.

Palavras-chave: Fontes primárias. Edição. Cartas pessoais. Não ilustres. 


\section{Apresentação}

O trabalho filológico aqui realizado tem como propósito a preservação e divulgação da memória de um grupo familiar cujas redes se materializam, em sua maioria, em diversos estados da região sudeste do Brasil. Os materiais levantados foram editados sob os rigorosos preceitos da Filologia, entendida aqui como Crítica Textual (CAMBRAIA, 2005), de acordo com as normas do projeto Para uma História do Português Brasileiro, que poderão ser conferidas na seção seguinte, no que se refere à elaboração de edições semidiplomáticas.

O fundo documental homenageia Didola, uma mulher mineira que, apesar de todas as dificuldades financeiras e de outras ordens, tinha um carinho inestimável para com o próximo. Mulher religiosa, amiga, prima, irmã, mãe são algumas das características notáveis por meio de sua correspondência passiva. No atual estágio da pesquisa, o acervo está constituído de 28 cartas escritas por diferentes remetentes como irmãos, filha, primas e amigos em geral e de uma prova, no nível de Ensino Fundamental I, da década de 20.

A família, proprietária do fundo documental, disponibilizou a guarda dos documentos à pesquisadora Letycia Dias Mallet, membro dos laboratórios de Estudos Filológicos (LabEFil) e de História da Língua Portuguesa (HistLing), para que ela desenvolvesse pesquisas com os materiais no âmbito da Faculdade de Letras da Universidade Federal do Rio de Janeiro. Vale destacar também que a família concorda com a publicação e com a divulgação de pesquisas realizadas com base nos documentos do Fundo Documental Didola. No atual estágio da pesquisa, os documentos estão armazenados no espaço físico desses laboratórios e, futuramente, serão disponibilizados on-line.

Disponibilizamos, aqui, um dos documentos editados e já trabalhados. Os objetivos são, primeiramente, o de preservação da memória desta família; o de disponibilizar um documento escrito por uma mulher não-ilustre, que ocupava a posição de tesoureira da prefeitura de Guaçuí, no Espírito Santo, na década de 60; e o de fornecer uma fonte primária - assim como forneceram Oliveira e Mendes (2019), Dores (2019) e Morais (2019) - que possibilita pesquisas em diversas áreas, como: estudos de cunho antropológico a partir do conteúdo, estudos de cunho linguístico a partir da língua e estudos de cunho filológico a partir do documento como um todo.

Após a apresentação das normas, trazemos a edição do documento selecionado, de código DID16-23-09-1967, parte de um arquivo pessoal. O testemunho, de tipologia textual carta, é autógrafo e seu registro, manuscrito. O documento, datado de 23 de setembro de 1967, foi escrito em Guaçuí (Espírito Santo - Brasil). A relação social estabelecida entre remetente (N.) e destinatário (D.) se dá no âmbito familiar: N. e D. são irmãs. No documento, a remetente conta como foram os preparativos e o 
seu casamento, além de realizar comentários sobre a família do noivo. É composto por dois fólios (reto, verso e reto) e possui aproximadamente 357 palavras.

\section{Normas de edição utilizadas}

Nesta seção, apresentamos as normas seguidas no Laboratório de Estudos Filológicos (LabEFil) e no Laboratório de História do Português Brasileiro (HistLing), no que tange a elaboração de edições semidiplomáticas. Tais laboratórios tomaram por base as "Normas de Transcrição de Documentos Manuscritos e Impressos - Edição Semidiplomática"1 do Projeto "Para a História do Português Brasileiro (PHPB)", elaboradas em 2010, e introduziram algumas modificações. As normas utilizadas foram as seguintes:

1. A transcrição será de natureza conservadora.

2. As variações alográficas de um mesmo grafema serão uniformizadas.

3. As abreviaturas, alfabéticas ou não, serão desenvolvidas, marcando-se em itálico as letras omitidas na abreviatura e observando-se os seguintes casos:

a) Respeitar, sempre que possível, a grafia do documento, ainda que manifeste idiossincrasias ortográficas do escriba, como no caso da ocorrência "munto", que leva a abreviatura "m. ${ }^{\text {to" a ser }}$ transcrita "munto".

b) No caso de variação no próprio documento ou em coetâneos, a opção será para a forma mais produtiva ou, na ausência dessa, da mais próxima da atual, como no caso de ocorrências "Deos" e "Deus", que levam a abreviatura "D." a ser transcrita "Deus".

c) As únicas abreviaturas não desenvolvidas foram as introduzidas com o objetivo de manter o anonimato dos envolvidos em documentos com menos de cem anos.

4. Será estabelecida fronteira de palavras que venham escritas juntas, mas não se introduzirá hífen ou apóstrofo onde não houver.

5. A pontuação original será rigorosamente mantida.

6. A acentuação original será rigorosamente mantida.

7. Os sinais de separação de sílaba ou de linha, usados pelos autores dos diversos documentos, serão mantidos como no original. Exemplos: "; "atira- I mos" e "atira= | mos".

\footnotetext{
${ }^{1}$ Disponíveis em <https://sites.google.com/site/corporaphpb>. Acesso em 12 set 2018.
} 
8. Será respeitado o emprego de maiúsculas e minúsculas como se apresentam no original. No caso de alguma variação física dos sinais gráficos resultar de fatores cursivos, não será considerada relevante. Assim, a comparação do traçado da mesma letra deve propiciar a melhor solução.

9. A divisão das linhas do documento original será preservada. A edição será justalinear.

10. A mudança de fólio ou página receberá a marcação entre colchetes conforme o caso:

a) Se em documentos manuscritos, com o respectivo número e indicação de frente ou verso. Exemplos: [fol. 1r]; [fol. 1v]; [fol. 2r]; [fol. 2v]; [fol. 3r]; [fol. 3v]; [fol. 16r].

b) Se em documentos impressos, indicação de página. Exemplos: [p. 1]; [p. 2]; [p. 3]; [p. 19].

11. Na edição, as linhas serão numeradas de cinco em cinco a partir da quinta. Essa numeração será encontrada à margem direita da mancha, à esquerda do leitor. Será feita de maneira contínua por fólio ou página.

12. As assinaturas, se legíveis, serão transcritas normalmente em documentos datados de cem anos desde a morte dos envolvidos. Caso contrário, serão sinalizadas como [assinatura].

13. Informações que o editor julgar significativas sobre a diagramação e layout do texto em impressos devem aparecer em nota de rodapé. 


\section{Edição do documento}

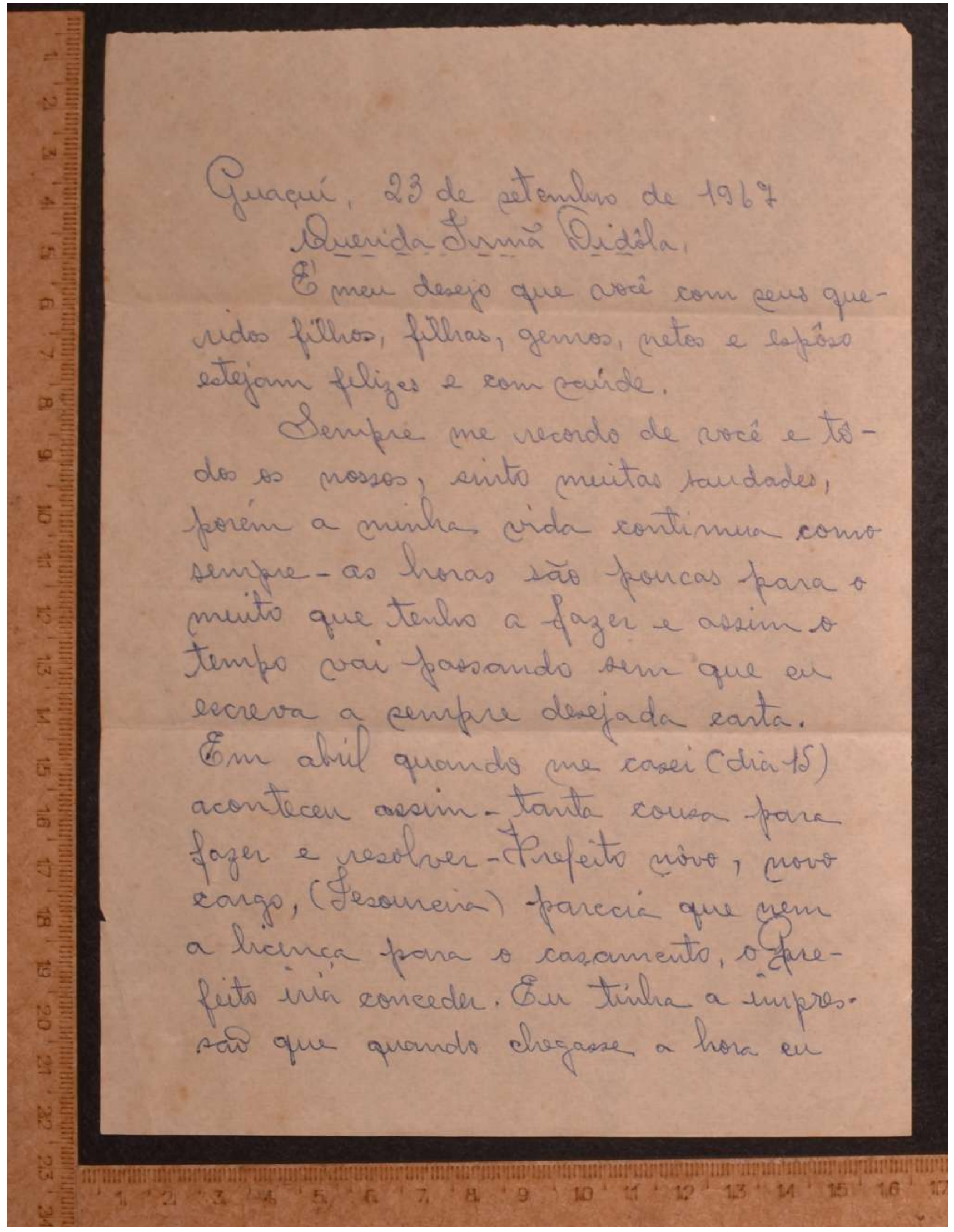


[fol. 1r]

Guaçuí , 23 de setembro de 1967

Querida Irmã D.

É meu desejo você com seus que-

ridos filhos, filhas, genros, netos e espôso

5 estejam felizes e com saúde.

Sempre me recordo de você e tôdos os nossos, sinto muitas saudades, porém a minha vida contimua como sempre _ as horas são poucas para o

10 muito que tenho a fazer e assim o tempo vai passando sem que eu escreva a sempre desejada carta. Em abril quando me casei (dia 15) aconteceu assim _ tanta cousa para

15 fazer e resolver_ Prefeito nôvo, novo cargo, (Tesoureira) parecia que nem a licença para o casamento, o Prefeito iria conceder. Eu tinha a impressão que quando chegasse a hora eu 


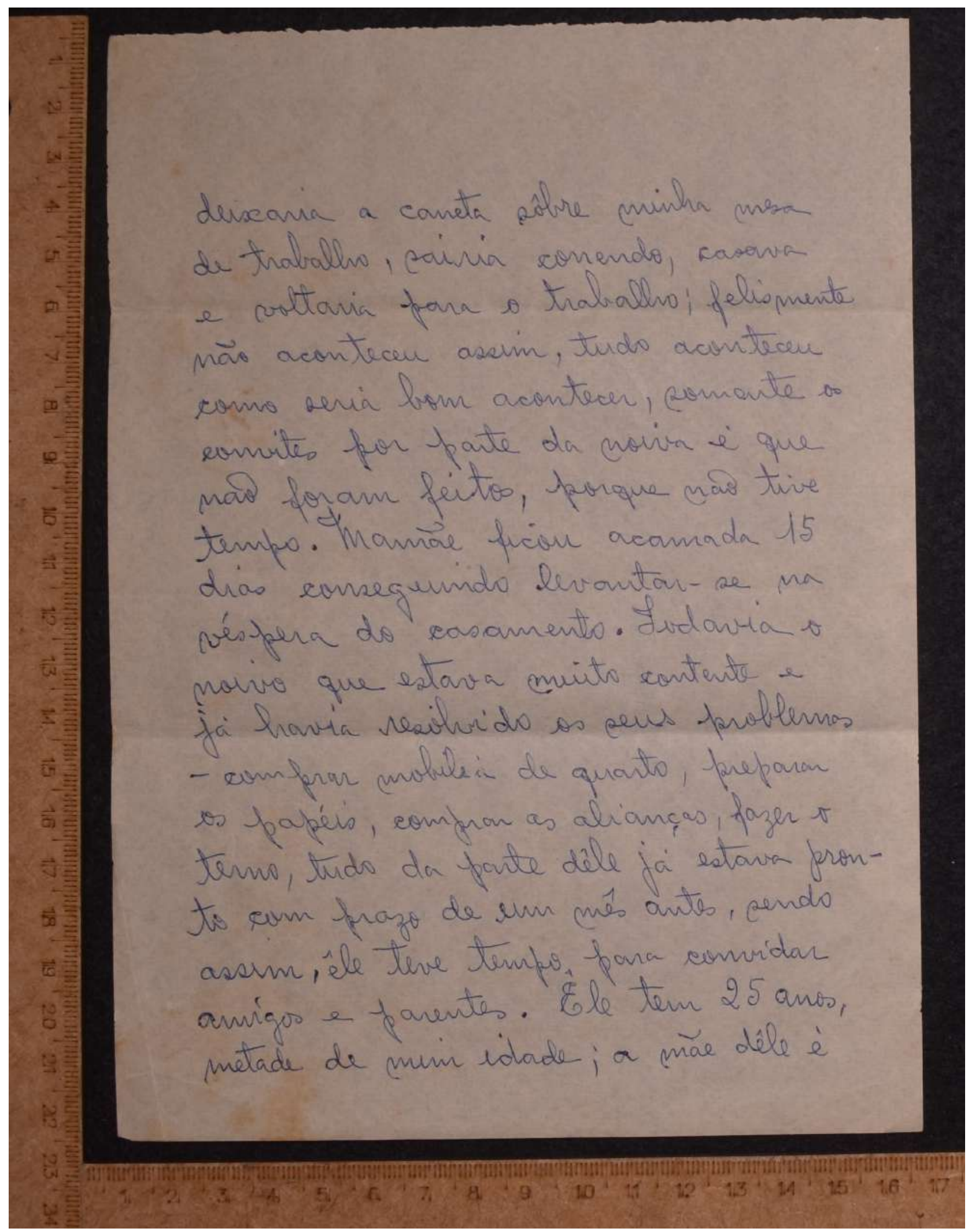


[fol. 2r]

deixaria a caneta sôbre minha mesa

de trabalho, sairia correndo, casava

e voltaria para o trabalho, felismente

não aconteceu assim, tudo aconteceu

5 como seria bom acontecer, somente os

convites por parte da noiva é que

não foram feitos, porque não tive

tempo. Mamãe ficou acamada 15

dias conseguindo levantar-se na

10 véspera do casamento. Todavia o

noivo que estava muito contente e

já havia resolvido os seus problemas

- comprar mobilia de quarto, preparar

os papéis, comprar as alianças, fazer o

15 terno, tudo da parte dêle já estava pron-

to com prazo de um mês antes, sendo

assim, êle teve tempo para convidar

amigos e parentes . Êle tem 25 anos,

metade de mim idade; a mãe dêle è 


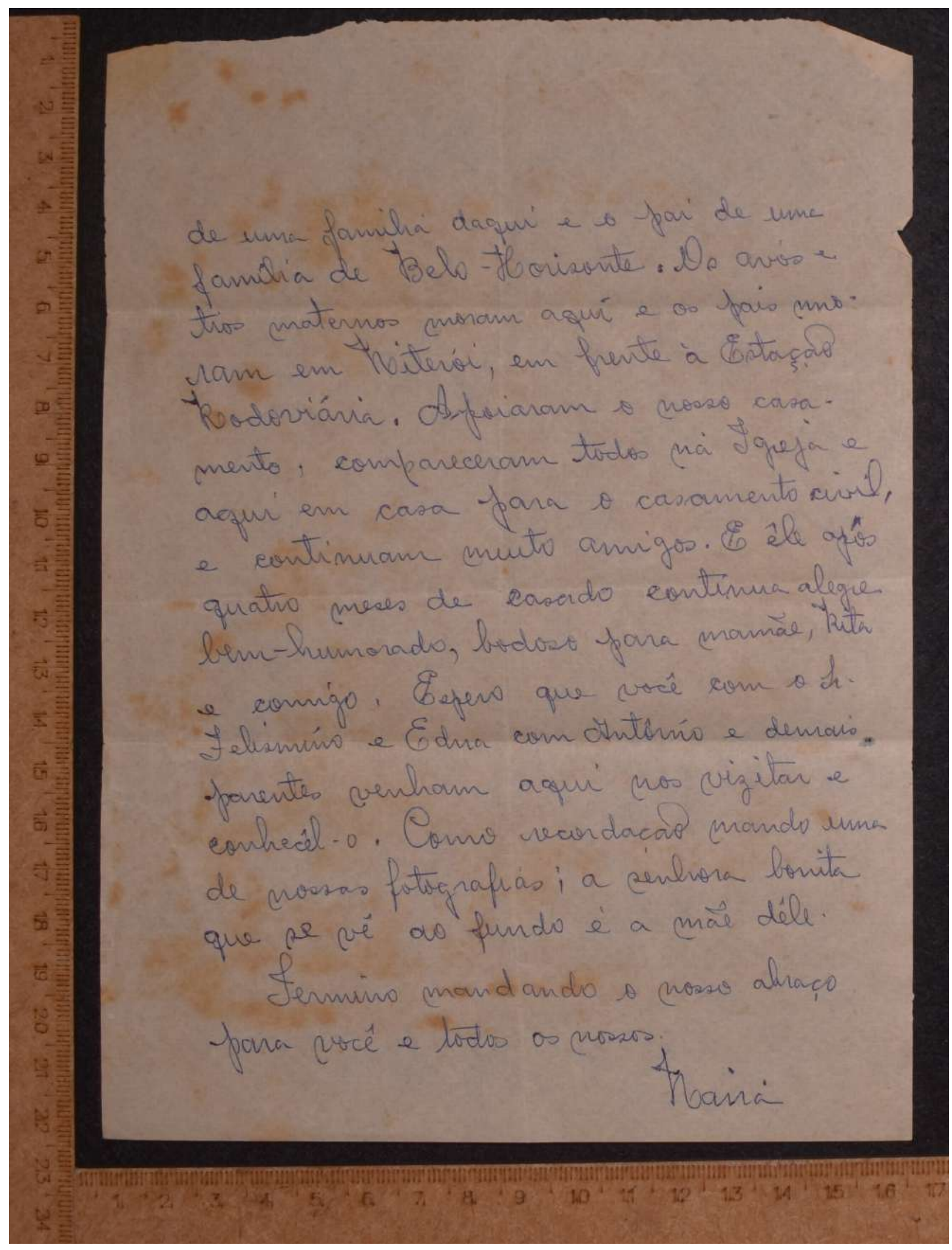


[fol. 3r]

de uma familia daqui e o pai de uma família de Belo - Horisonte . Os avós e tios maternos moram aquí e os pais moram em Niterói, em frente à Estação

5 Rodoviária. Apoiaram o nosso casamento, compareceram todos ná Igreja e aquí em casa para o casamento civil, e continuam muito amigos. E êle apôs quatro meses de casado continua alegre

10 bem-humorado, bondoso para mamãe, Rita e comigo . Espero que você com o Senhor F. e E. com A. e demais parentes venham aqui nos vizitar e conhecêl-o . Como recordação mando uma

15 de nossas fotografias ; a senhora bonita que se vê ao fundo é a mãe dêle.

Termino mandando o nosso abraço para você e todos os nossos.

N. 


\section{Referências bibliográficas}

OLIVEIRA, C. B.; MENDES, S. T. do P. Testamento do Rei Dom Pedro II, de Portugal, ano de 1704. LaborHistórico, v. 5, n. 1, 2019. p. 240-285. Disponível em: https://doi.org/10.24206/lh.v5i1.25447.

CAMBRAIA, C. N. Introdução à crítica textual. São Paulo: Martins Fontes, 2005.

DORES, M. V. P. das. Relação dos trastes de prata e ornamentos da extinta capela de Santo Antônio (1856). LaborHistórico, v. 5, n. 1, 2019. p. 286-297. Disponível em: https://doi.org/10.24206/lh.v5i1.24859.

MORAIS, K. C. Nada a declarar: as Atas da Câmara de Jundiaí de 1663 a 1669. LaborHistórico, v. 5, n. 1, 2019. p. 230-239. Disponível em: https://doi.org/10.24206/lh.v5i1.25019.

PROJETO para a História do Português Brasileiro (PHPB). Normas de transcrição de documentos manuscritos e impressos. Disponível em: https://sites.google.com/site/corporaphpb/. 